\title{
A Ciência, a Natureza da Ciência e o Ensino de Ciências
}

\author{
Odete Pacubi Baierl Teixeira ${ }^{1}$ \\ https://orcid.org/0000-0001-7513-8336
}

O modelo tradicional de ensino, fundamentado quase que exclusivamente na ideia de uma educação dogmática, sustentada na acumulação passiva de conhecimentos, ficando o papel do professor restrito à transmissão de conhecimentos, e o do aluno a um mero receptor e repetidor, é questionado já faz algum tempo nas pesquisas educacionais. Os modos de entender de cada um precisam ser considerados, pois várias cadeias de significados surgem como resultado, sendo que no espaço escolar, principalmente, três elementos estão presentes: o professor, o aluno e o conteúdo. A escola, entendida como uma instituição social, tem como um de seus compromissos propiciar a articulação de saberes específicos de diferentes áreas de conhecimentos com os seus alunos, apresentando vínculos com um conjunto de conhecimentos organizados, sistematizados, validados e aceitos por determinada comunidade científica. A forma como são realizadas a seleção de conteúdos e as propostas e condução das atividades são determinantes para a aprendizagem, ressaltando-se, ainda, a diversidade existente quando focamos um grupo de pessoas, no que diz respeito às particularidades e às peculiaridades de cada um dos envolvidos.

O processo de ensino e de aprendizagem precisa levar em conta a importância e a necessidade de se promover capacidades de pensamento, no sentido de ocorrer uma aquisição do conhecimento para o entendimento de debates científicos, de questões ligadas à tecnologia, e de compreensão das interações complexas envolvendo Ciência e Sociedade.

Se voltarmos nossa atenção para os conteúdos relacionados às Ciências, verificaremos uma forma própria e particular na produção dos sentidos e de interpretação, na qual existe o envolvimento, por exemplo, com teorias, leis, conceitos, fórmulas, axiomas, e também com diferentes formas de representações como equações, gráficos, sinais, diagramas, dentre tantas outras.

Vale a pena ressaltar Heisenberg (1985) quando afirma que a Ciência não nos fala da natureza, mas nos oferece respostas às perguntas sobre a natureza: o que observamos não é a natureza em si mesma, mas a natureza por meio do nosso método de questionar. Contextos diferentes organizam os fatos de formas diferentes, levando a interpretações diferentes, pois as referências se restringem a certas particularidades. A Ciência não é a realidade, nem tampouco representa a realidade, mas interpreta a realidade por intermédio de relações dependentes de teorias e modelos, possibilitando a construção e a reconstrução de conhecimentos.

\footnotetext{
${ }^{1}$ Universidade Estadual Paulista (UNESP), Faculdade de Ciências, Programa de Pós-graduação em Educação para a Ciência, Bauru, SP, Brasil. E-mail: opbt@terra.com.br
} 
Um fazer Ciência, conforme aponta Lemke (1977), comportaria: observar, descrever, comparar, classificar, analisar, discutir, levantar hipóteses, teorizar, questionar, desafiar, argumentar, sugerir procedimentos, julgar, avaliar, decidir, concluir, generalizar, informar, escrever, ler, de modo que o uso da linguagem das Ciências deve ser colocada de maneira a propiciar habilidades relacionadas à compreensão, domínio e prática no ensino científico. Deve ser ressaltado, portanto, o importante papel do professor, tendo em vista que sua intervenção deve ser intencionada e fundamentada, buscando recursos estratégicos para manter os seus alunos engajados no enfrentamento de desafios. Ensinar Ciência está relacionado a uma aprendizagem que leve em conta o envolvimento dos alunos em novas formas de pensar: existe a necessidade de uma articulação com os modelos próprios da Ciência, envolvendo o aluno numa cultura científica, envolvendo-o, por exemplo, na busca de soluções de problemas e na tomada de decisões, atuando com capacidade crítica na desmistificação de crenças e valores, na não neutralidade da Ciência, na interferência de determinantes de origem política e sociocultural.

Relacionadas a algumas das breves considerações relacionadas ao fazer Ciência, ao ensinar Ciência, e ao falar sobre Ciência, a coletânea do presente volume comporta artigos que trazem contribuições importantes tanto para pesquisadores como professores que estão envolvidos com a temática.

O artigo Natureza da Ciência (NOS) discute a importância da nature of science na formação de professores, sendo que tão importante quanto saber conteúdos de ciência, deve-se saber sobre ciência, em todas as suas nuances. $\mathrm{O}$ artigo Los desafios epistemológicos de la educación científica para el desarrollo de la agricultura en Cuba trata de questões epistemológicas da educação científica, principalmente no que diz respeito à sustentabilidade, que envolve produção de conhecimentos e tecnologias.

Quatro artigos abordam três relevantes aspectos ligados ao ensino e a aprendizagem no ensino de Ciências: o livro didático, a experimentação, e a inserção da abordagem histórica e historiografia.

Não é desconhecido que o livro didático é um suporte muito utilizado pelos professores como orientação para as suas atividades, por isso merece uma atenção especial, pois transmite valores ideológicos e culturais, principalmente em assuntos que possam gerar polêmica. É nesse sentido que o artigo Livro didático como artefato cultural analisa, por intermédio de uma abordagem teórica, o entorno envolvendo a temática, no que concerne aos processos culturais, históricos, sociais e políticos.

A área de investigações sobre a utilização de experimentos como uma estratégia de ensino, com o objetivo de possibilitar uma melhor compreensão sobre os limites e as possibilidades para trazer subsídios para que o professor possa realizar o seu trabalho em sala de aula é bastante ampla. O grau de direcionamento das atividades, que também pode ser variada, envolve desde uma verificação até uma investigação, passando por diferentes graus, de demonstração e de simulação, entre outras. No artigo Estudos dos roteiros disponibilizados em repositórios virtuais por meio do ensino por investigação são analisados roteiros de experimentos disponibilizados no portal do professor do MEC, identificando elementos sobre a organização de como as atividades são contextualizadas, e a interatividade que propiciam aos alunos.

A importância sobre a inserção da abordagem histórica e da historiografia no contexto educacional pode ser observada pelo aumento das pesquisas que tratam da análise histórica, em que são identificadas as influências sociais, políticas, econômicas, pessoais, dentre outras. Ainda que historiadores possam chegar a diferentes explicações e conclusões, mesmo estudando o mesmo conjunto de fatos, acontecimentos e situações que ocorreram no passado, produzindo respostas diferentes para a mesma pergunta, não podemos deixar de destacar 
que o debate acadêmico pode subsidiar o entendimento envolvendo a evolução de conteúdos específicos. Nessa coletânea três textos versam sobre a abordagem histórica e historicidade: no artigo Abordagem histórica do sistema circulatório bumano a pesquisa foi feita com alunos de uma licenciatura que procuraram integrar atividades envolvendo aspectos históricos relacionados ao sistema circulatório humano; no artigo historiográfico intitulado Estudo das historiografias de Paul Karlson, Konstantin Ríbnikov, Howard Eves e Bento de Jesus Caraça são trazidas contribuições da história do conceito de função principalmente para o público que está envolvido com o ensino de Matemática; e no artigo Circulação inter e intracoletiva em grupos de pesquisa de história da educação matemática são abordadas as interações de quatro grupos que investigam a História da educação matemática no estado de Santa Catarina.

O artigo Ensino de fraçôes para adolescentes com deficiência visual trata da educação especial no desenvolvimento de materiais concretos e de intervenções que podem auxiliar o entendimento de frações. Na perspectiva da educação ambiental, o artigo Percep̧̧ão e paisagem no cotidiano de escolas inseridas em paisagens rurais e urbanas discute a percepção sobre meio ambiente de alunos de escolas localizadas em diferentes entornos.

Sobre a formação de professores, o artigo $A$ identidade formativa do professor de matemática de escolas rurais aborda aspectos que interligam o saber matemático com os contextos da educação rural. No artigo Uma abordagem centrada no aluno para ensinar química são investigados diferentes ambientes de aprendizagem que propiciassem uma maior participação dos alunos. A construção da autonomia, da criatividade e da valorização da subjetividade é analisada no artigo Os conceitos de formação e semiformação de Adorno na análise do processo de construção de trabalhos de conclusão de curso, sobre questões sociocientíficas, na graduação em Pedagogia. No âmbito da formação continuada de professores, o artigo A formação continuada do professor de educação infantil em educação ambiental analisa a forma como professores estruturam e planejam atividades envolvendo a educação ambiental.

Ainda que a sala de aula seja um dos lugares onde grande parte dos sujeitos se deparam com os conhecimentos, não podemos deixar de salientar a importância de outros espaços, que também assumem relevância quando a intenção é a de formação de cidadãos cientificamente cultos, envolvendo não somente uma aprendizagem da Ciência, mas também um aprender a fazer Ciência e aprender sobre a Ciência. Salientamos aqui os Museus e Centros de Ciência, em que o papel dos mediadores é crucial para que os sujeitos possam se envolver e usufruir ao máximo das visitas. No artigo Diálogo com mediadores de museus de ciência que trata, especificamente, do Instituto Nacional da Mata Atlântica de Santa Teresa, no Espírito Santo, é realizada uma análise sobre o papel no desempenho da mediação, e a função social dos mediadores na aprendizagem. Um outro canal para a formação de cidadãos cientificamente cultos está ligado as revistas de divulgação científica, e nesse contexto, a coletânea da presente edição traz um artigo que analisa a seção Eu li, eu leio da revista Ciência Hoje das Crianças, envolvendo a trajetórias de sucesso profissional ou forte relação com a Ciência de leitores atuais e de ex-leitores.

Finalizando e corroborando com a importância do engajamento de questões relacionadas à cultura científica em seus vários domínios, e como exemplo de uma experiência particular, gostaria de compartilhar a narrativa de uma professora das séries iniciais do ensino fundamental que participou de um curso de formação continuada, quando foi solicitada que falasse sobre as suas memórias:

Mas é difícil achar o material, e outra, nem sempre a gente sabe as coisas. Um dia eu estava fazendo a experiência do ovo que afunda na água sem sal e flutua na água com sal. Sabe essa, não é? Então! Eu estou lá explicando, aí um aluno falou que a água tem uma espécie de plástico que não deixa as 
coisas afundarem. Aí eu não sabia e fiquei olhando para ele sem saber o que dizer. Aí eu perguntei para ele onde ele havia ouvido aquilo. Aí ele me falou que assiste 'O Mundo de Beakmam' e que o Beakmam explicou que esse plástico era o que permitia determinados insetos andarem sobre as águas. Aí eu fiquei perdida, não sabia dizer nem sim e nem não. Concordei com ele e nunca mais fiz experiência alguma, porque eles podem fazer perguntas ou afirmações que a gente não vai saber responder. Então eu prefiro ficar com o ponto do livro mesmo. (MONTEIRO, 2002, p. 113-114).

\section{Referências}

HEISENBERG, W. La imagen de la natureza en la fisica actual. Barcelona: Orbis, 1985.

LEMKE, J. L. Aprender a hablar ciencia: lenguaje, aprendizaje y valores. Buenos Aires: Editorial Paidos, 1977.

MONTEIRO, M. A. A. Interações dialógicas em aulas de ciências nas séries iniciais: um estudo do discurso do professor e as argumentações construídas pelos alunos. 2002. Dissertação (Mestrado em Educação para a Ciência) - Faculdade de Ciências, Universidade Estadual Paulista, Bauru, 2002. 